\title{
A challenging case of transsexualism
}

\author{
$P$ Ginige, $\mathrm{H} \mathrm{K} \mathrm{K} \mathrm{I} \mathrm{de} \mathrm{Alwis}$
}

\section{Abstract}

A transsexual is an individual who seeks or has undergone a transition to the preferred sex. A 39-yearold man presented expressing the strong desire to change his sex to that of a female. He said he started feeling and behaving like a female and had homosexual relationships with boys at the age of 10-12 years. He had later started a relationship with a woman, and had an open marriage with her. But he reported having no sexual desire towards his wife or his casual male partners, and reported feeling guilty after sexual interactions with both parties. He had stopped sexual activities altogether over the one and half years preceding presentation, reportedly due to lack of desire, and had started taking ethinyl estradiol to become a woman. During this time he had also separated from his wife, because the latter had commenced a committed relationship with a different man. Six months subsequently, he approached healthcare services, seeking help for a sex change. On examination he presented as a pleasant young male, with mild feminine gestures. His wife claimed she was unaware that he was unhappy in his male sex. When the patient was referred for a second opinion, he became verbally abusive. Although this patient fulfilled the criteria for transsexualism, there were also other psycho-social features, such as depression, grief, and personality traits, which extended beyond the stereotypical sexual orientation that determines gender identity. The case exemplifies the complexities and challenges in diagnosing and managing gender dysphoria.

Key words: transsexualism, management, depression

SL J Psychiatry 2021; 12(2): 44-46

\section{Introduction}

The term transsexualism is used when an individual seeks or has undergone a social transition from birth sex to preferred sex, usually involving treatment with hormones or surgery (1). The condition lies within the diverse spectrum of gender dysphoria. The current management of transsexualism is based mainly on guidelines prepared on expert consensus rather than a robust evidence base. The case exemplifies how transsexualism demands a deeper and wider understanding, given the complexities of its presentations.

\section{Case Report}

NS was a 39-year-old married businessman who presented expressing the need to become a woman. He reported that he had wished to be of the female sex from the age of ten years. He had behaved and felt like a boy until then. He started living in a female role increasingly thereafter, for which he was bullied by his friends and scorned by family, mainly his father. NS became distressed due to this, and tried to "be a man" as per the wish of his father, by bodybuilding and taking male hormones in his twenties.
He had several sexual relationships with boys in the school, where he was the submissive feminine partner. The sexual activities were limited to kissing, stroking and fondling. He felt emotionally close to his partners and felt lonely when they left him for female partners. He started a relationship with a 16-year-old girl at the age of 19-years and married her after a courtship of five years. It was an open marriage, with both having separate sexual partners of their own. He denied having group sex. NS and his wife engaged in vaginal sexual intercourse with him as the male partner. He had an adequate erection and he also engaged his wife to penetrate his anus with a prosthetic penis for sexual pleasure. He denied practicing anal intercourse as the male penetrating partner in his homosexual relationships.

He reported having periods of feeling sad, worthless and inactive intermittently throughout his life. He said though he engaged in sex with his wife and the casual male partners, he did it with no desire, and he always felt guilty following the sexual acts. There had been times when he had felt suicidal, but he had never attempted to harm himself. He has stopped engaging in sexual activities for the past one and half years, due to lack of 
desire. He had been using over the counter ethinyl estradiol for 7-8 months. His wife had commenced a stable relationship with another man during this time. NS decided to separate from her and started living independently over the past 6 months, which had been against the wish of his wife, who had wanted them to remain together. He has felt increasingly sad when he saw transgender people and a few months after the separation from his wife he presented to services for treatment. He had a pattern of harmful use of alcohol. By nature he was an impulsive and hot tempered character, who would get easily frustrated.

On examination he was a pleasant young man, who looked like a male with only mild feminine gestures and body language. His mood was depressed. He expressed a strong desire to become a woman, but did not answer the question whether he would request a transition if he was still in a relationship with his wife. He was suffering from moderate depression, and was preoccupied about not being able to fulfill his desire to be a woman. His wife claimed that he has always been a male. She said she was not aware that he wanted to change his sex, and expressed great distress over his wish. It was decided to assess NS in greater detail before starting the transition, at which NS became very angry and was verbally abusive towards his wife and the first author. A continuous flow of text messages to the clinic WhatsApp number, expressing his sadness, distress, disgust and anger for not being able to start the transition, with intermittent threats to kill himself, followed. We responded acknowledging his distress and frustration, offering support and were able to engage him again. It was decided to obtain a second opinion regarding his diagnosis and this was explained to him in a clear and non-threatening manner. NS agreed at first, but subsequently again became verbally abusive towards the clinicians and refused to engage. It was decided to direct NS to another psychiatrist for support, as the therapeutic relationship was adversely affected.

\section{Discussion}

NS fulfilled the criteria for transsexualism. However, there are grey areas which made us question his gender dysphoria. NS was not an adolescent whose gender identity was still being formed but an adult close to 40 years. He reportedly did not have any feminine behavior during very early childhood. His homosexual activities started around early adolescence, and he started experiencing gender dysphoria parallel to these encounters. Gender is a fluid construct and psychosocial factors influence expression of gender identity (2). His relationship with boys when his gender identity was being formed might have played a role in his gender dysphoria.
Yet, every adolescent who experiences homosexual activities does not develop a gender dysphoria (3). His borderline personality traits in him may have influenced his gender identity (4). The ongoing undetected and untreated depression also may influence the clinical picture markedly.

Though he expressed a desire to become a woman we wonder whether he would seek to change sex if his wife did not commence another relationship. It is possible he did not want to lose the emotional stability he felt with his wife by changing to the desired sex. Sexual orientation and gender identity are affected by grief and depression. Depression needs to be treated in order to commence the gender transition process. Overall he appeared to be a trans female with bisexual orientation.

\section{Conclusions}

The case exemplifies the diagnostic difficulties in this field, particularly when there are comorbid challenging personality traits and mental health disorders. Internal as well as external transphobia could force trans individuals to live a life they do not enjoy. A wider understanding of the unique struggles of each transsexual individual is needed in order to address their complex issues successfully.

\section{Conflicts of interest}

None.

\section{Author contributions}

PG contributed to the conception/ design of the work, gathering information and revising the draft critically for important intellectual content. HKKIA acquired detailed information and drafted the report and contributed to the analysis. Both authors have approved the final version and are accountable for all aspects of the work.

P Ginige, Department of Psychiatry, Faculty of Medicine, University of Peradeniya, Sri Lanka

H K K I de Alwis, Psychiatry Unit, Teaching Hospital Peradeniya, Sri Lanka

Corresponding author: H K K I de Alwis

Email: Kusumindra@gmail.com

http://orcid.org/0000-0003-4818-0322 


\section{References}

1. ICD-10, the ICD-10 classification of mental and behavioural disorders. Geneva: World Health Organization; 1992.

2. Zucker K, Lawrence A, Kreukels B. Gender Dysphoria in Adults. Annual Review of Clinical Psychology. 2016; 12(1): 217-47.

3. Heylens G, Elaut E, Kreukels B, Paap M, Cerwenka S,
Richter-Appelt $\mathrm{H}$, et al. Psychiatric characteristics in transsexual individuals: multicenter study in four European countries. British Journal of Psychiatry 2014; 204(2): 151-6.

4. Bosnjak D, Sabo T, Makaric P. Gender Identity Disorder or a Symptom of Borderline Disorder - A Case Report. Presentation presented at; 2019; $27^{\text {th }}$ European Congress of Psychiatry. 